\title{
The European/International Fibromuscular Dysplasia Registry and Initiative (FEIRI)-clinical phenotypes and their predictors based on a cohort of 1000 patients
}

Citation for published version (APA):

Pappaccogli, M., Di Monaco, S., Warchol-Celinska, E., Lorthioir, A., Amar, L., Aparicio, L. S., Beauloye, C., Bruno, R. M., Chenu, P., de Leeuw, P., De Backer, T., Delmotte, P., Dika, Z., Gordin, D., Heuten, H., Iwashima, Y., Krzesinski, J. M., Kroon, A. A., Mazzolai, L., ... Working Group 'Hypertension and the Kidney' of the European Society of Hypertension (ESH) (2021). The European/International Fibromuscular Dysplasia Registry and Initiative (FEIRI)-clinical phenotypes and their predictors based on a cohort of 1000 patients. Cardiovascular Research, 117(3), 950-959. https://doi.org/10.1093/cvr/cvaa102

Document status and date:

Published: 01/03/2021

DOI:

10.1093/cvr/cvaa102

Document Version:

Publisher's PDF, also known as Version of record

\section{Document license:}

Taverne

Please check the document version of this publication:

- A submitted manuscript is the version of the article upon submission and before peer-review. There can be important differences between the submitted version and the official published version of record.

People interested in the research are advised to contact the author for the final version of the publication, or visit the DOI to the publisher's website.

- The final author version and the galley proof are versions of the publication after peer review.

- The final published version features the final layout of the paper including the volume, issue and page numbers.

Link to publication

\footnotetext{
General rights rights.

- You may freely distribute the URL identifying the publication in the public portal. please follow below link for the End User Agreement:

www.umlib.nl/taverne-license

Take down policy

If you believe that this document breaches copyright please contact us at:

repository@maastrichtuniversity.nl

providing details and we will investigate your claim.
}

Copyright and moral rights for the publications made accessible in the public portal are retained by the authors and/or other copyright owners and it is a condition of accessing publications that users recognise and abide by the legal requirements associated with these

- Users may download and print one copy of any publication from the public portal for the purpose of private study or research.

- You may not further distribute the material or use it for any profit-making activity or commercial gain

If the publication is distributed under the terms of Article $25 \mathrm{fa}$ of the Dutch Copyright Act, indicated by the "Taverne" license above, 


\title{
The European/International Fibromuscular Dysplasia Registry and Initiative (FEIRI)_clinical phenotypes and their predictors based on a cohort of 1000 patients
}

\author{
Marco Pappaccogli (1) ${ }^{1,2,3 \dagger}$, Silvia Di Monaco ${ }^{1}{ }^{1 \dagger}$, Ewa Warchoł-Celińska ${ }^{4}$,
} Aurélien Lorthioir $\mathbb{1}^{5}{ }^{5}$, Laurence Amar ${ }^{5,6}$, Lucas S. Aparicio $\mathbb{1}^{7}$, Christophe Beauloye ${ }^{2,3}$, Rosa Maria Bruno (1) ${ }^{8,9}$, Patrick Chenu ${ }^{2,3}$, Peter de Leeuw ${ }^{10}$, Tine De Backer ${ }^{11}$, Philippe Delmotte ${ }^{12}$, Zivka Dika ${ }^{10}{ }^{13}$, Daniel Gordin ${ }^{10}{ }^{14,15,16}$, Hilde Heuten ${ }^{17}$, Yoshio Iwashima ${ }^{18}$, Jean-Marie Krzesinski ${ }^{10}{ }^{19,20}$, Abraham A. Kroon (1) ${ }^{10}$, Lucia Mazzolai ${ }^{21}$, Esteban Poch ${ }^{20}{ }^{22}$, Pantelis Sarafidis $\mathbb{C}^{23}$, Christophe Seinturier ${ }^{24}$ Wilko Spiering ${ }^{25}$, Laurent Toubiana ${ }^{26}$, Patricia Van der Niepen ${ }^{20}{ }^{27}$, Daan van Twist ${ }^{28}$, Adriana Visonà ${ }^{29,30}$, Jean-Claude Wautrecht $\mathbb{1}^{31}$, Helena Witowicz ${ }^{4}$, Jianzhong $\mathrm{Xu}^{32}$, Aleksander Prejbisz (1) ${ }^{4}$, Andrzej Januszewicz ${ }^{4}$, Michel Azizi ${ }^{5,6}$, and Alexandre Persu ${ }^{2,3 *}$, the European/International FMD Registry and Initiative (FEIRI), and the Working Group 'Hypertension and the Kidney' of the European Society of Hypertension (ESH)

\footnotetext{
${ }^{1}$ Division of Internal Medicine and Hypertension Unit, Department of Medical Sciences, University of Turin, Turin, Italy; ${ }^{2}$ Division of Cardiology, Cliniques Universitaires Saint-Luc, Université Catholique de Louvain, 10 Avenue Hippocrate, 1200 Brussels, Belgium; ${ }^{3}$ Pole of Cardiovascular Research, Institut de Recherche Expérimentale et Clinique, Université

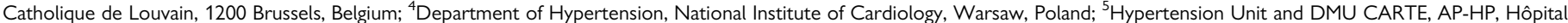

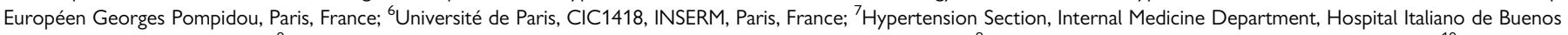

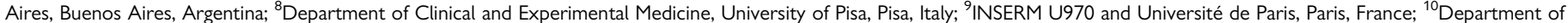
Medicine, Maastricht University Medical Center, Maastricht, The Netherlands; ${ }^{11}$ Department of Cardiovascular Diseases, University Hospital Ghent, Ghent, Belgium; ${ }^{12}$ Hypertension

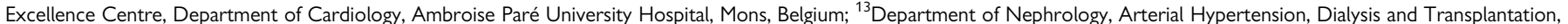

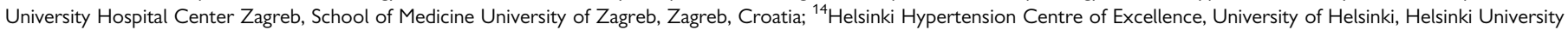

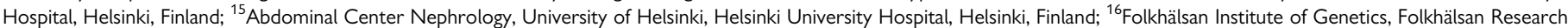

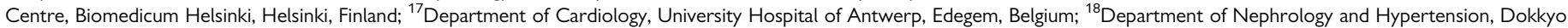
Medical University, Tochigi, Japan; ${ }^{19}$ Division of Nephrology, Department of Internal Medicine, University of Liège Hospital, Liège, Belgium; ${ }^{20}$ Groupe Interdisciplinaire de Génoprotéomique Appliquée (GIGA), Cardiovascular Sciences, University of Liège, Liège, Belgium; ${ }^{21}$ Division of Angiology, Heart and Vessel Department, Lausanne University

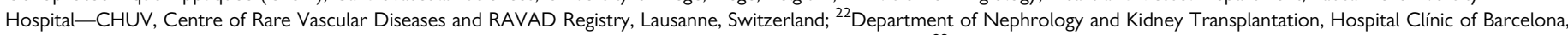

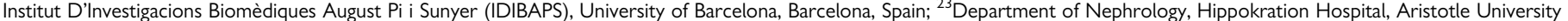

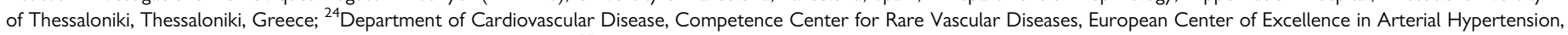
Grenoble-Alpes University Hospital, CS Grenoble Cedex 9. France; ${ }^{25}$ Department of Vascular Medicine, University Medical Center Utrecht, Utrecht University, Utrecht, The Netherlands; ${ }^{26}$ Sorbonne Université, Université Paris 13 , Sorbonne Paris Cité, INSERM, UMR_S1142, LIMICS, IRSAN, Paris, France; ${ }^{27}$ Department of Nephrology \& Hypertension,

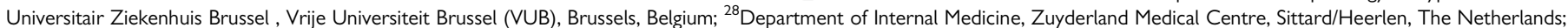

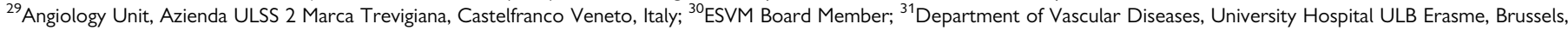
Belgium; and ${ }^{32}$ Shanghai Institute of Hypertension, Department of Hypertension, Ruijin Hospital, Shanghai Jiaotong University School of Medicine, Shanghai, China
}

Received 10 February 2020; revised 27 February 2020; editorial decision 6 April 2020; accepted 7 April 2020; online publish-ahead-of-print 13 April 2020

Time for primary review: 1 day

Aims from 22 countries. We present their characteristics according to disease subtype, age and gender, as well as predictors of widespread disease, aneurysms and dissections.

* Corresponding author. Tel: +32 2764 6306, +32 2764 2533; fax: +32 2764 8980, E-mail: alexandre.persu@uclouvain.be

${ }^{\dagger}$ The first two authors contributed equally to the study.

Published on behalf of the European Society of Cardiology. All rights reserved. @ The Author(s) 2020. For permissions, please email: journals.permissions@oup.com. 
Methods and results

Conclusions
All patients diagnosed with FMD (string-of-beads or focal stenosis in at least one vascular bed) based on computed tomography angiography, magnetic resonance angiography, and/or catheter-based angiography were eligible. Patients were predominantly women (82\%) and Caucasians (88\%). Age at diagnosis was $46 \pm 16$ years $(12 \%$ $\geq 65$ years old), $86 \%$ were hypertensive, $72 \%$ had multifocal, and 57\% multivessel FMD. Compared to patients with multifocal FMD, patients with focal FMD were younger, more often men, had less often multivessel FMD but more revascularizations. Compared to women with FMD, men were younger, had more often focal FMD and arterial dissections. Compared to younger patients with FMD, patients $\geq 65$ years old had more often multifocal FMD, lower estimated glomerular filtration rate and more atherosclerotic lesions. Independent predictors of multivessel FMD were age at FMD diagnosis, stroke, multifocal subtype, presence of aneurysm or dissection, and family history of FMD. Predictors of aneurysms were multivessel and multifocal FMD. Predictors of dissections were age at FMD diagnosis, male gender, stroke, and multivessel FMD.

\section{Introduction}

Fibromuscular dysplasia (FMD) is an idiopathic, segmental, nonatherosclerotic and non-inflammatory disease of the musculature of the arterial walls, leading to stenosis of small- and medium-sized arteries. ${ }^{1,2}$ Besides stenosis, other manifestations of FMD, such as aneurysms, dissections, and arterial tortuosity may also be identified. ${ }^{2}$ Renal and cerebrovascular arteries are more frequently involved, but all medium-sized arteries may be affected. ${ }^{2}$

While FMD is often asymptomatic and only diagnosed incidentally on the occasion of imaging tests performed for other reasons, ${ }^{3}$ in a number of cases, it may be at the origin of severe or even life-threatening complications. The clinical manifestations of FMD mostly depend on the vascular beds involved. Renal FMD may lead to hypertension, while cerebrovascular involvement may result in headache, pulsatile tinnitus, transient ischaemic attack, stroke and/or subarachnoid haemorrhage. ${ }^{2,4}$ The $U^{5}$ and French ${ }^{6}$ FMD registries have substantially improved our knowledge on the demographic characteristics, classification, prevalence, and clinical manifestations of FMD. Thanks to their joint efforts, along with those of other groups around the world, our conception of FMD has evolved from a rare cause of renovascular hypertension of young women to a systemic vascular disease which may be diagnosed at all ages, both in women and men with a wide range of manifestations. Current knowledge has been summarized in the First International Consensus on diagnosis and management of FMD. ${ }^{2}$

The European/International FMD registry ${ }^{7}$ was launched in December 2015 at the First Brussels National Meeting on FMD and subsequently endorsed by the European Society of Hypertension (ESH) in 2016. It currently includes more than 50 items concerning demographic and clinical characteristics, family history, type, site/s, associated lesions, and complications of FMD, as well as surgical or endovascular interventions. The online platform allows registering an indefinite number of visits, imaging, and vascular interventions for each patient. ${ }^{8,9}$ The European/ International Registry also includes contribution from existing registries, such as the French NOMADE and the Polish ARCADIA-POL registries. Finally the Registry is also associated with a DNA and RNA biobank and contributes to important research initiatives in the field.
The present analysis incorporates data from the first 1022 patients enrolled in the European/International FMD Registry with the aim of (i) describing the characteristics of patients presenting with FMD in a large and diverse multicentre cohort; (ii) comparing clinical and FMD characteristics between different subgroups of patients (patients with multifocal vs. focal FMD; men vs. women; patients $<65$ vs. $\geq 65$ years old); (iii) identifying predictors of multivessel disease, and of presence of FMD-related aneurysms and/or dissections.

\section{Methods}

The diagnosis of FMD was based on the identification of multifocal or focal FMD lesions in at least one arterial bed by computed tomography angiography, magnetic resonance angiography and/or catheter-based angiography, as recommended in the First International FMD Consensus. ${ }^{2}$ Multifocal FMD was defined as the presence of alternating areas of stenosis and dilatation ('string-of-beads' appearance), especially in the mid- and distal segments of the artery. Focal FMD was defined as the presence of a single stenosis occurring in any part of the artery in the absence of arguments in favour of atherosclerotic, inflammatory, or genetic arteriopathies. ${ }^{2}$ Rare patients with both multifocal and focal lesions were considered as being of the multifocal subtype. In agreement with the International Consensus, ${ }^{2}$ multivessel FMD was defined as the presence of multifocal or focal FMD lesions in at least two different arterial beds or, alternatively, FMD-related stenosis in one vascular bed and other FMD-related lesions in one or more vascular bed(s). The following vascular beds were taken into account: cerebrovascular, renal, visceral, upper and lower extremity arteries.

Both prevalent and incident patients aged $\geq 18$ years were eligible. Patients with suspicion of FMD only based on duplex ultrasound were excluded. Patients whose primary diagnosis was spontaneous coronary artery dissection were not eligible.

The study was approved by local and national Institutional Review Boards (IRBs), and informed consent was obtained according to national regulations. At the time of enrolment, the investigators filled an initial enrolment form in the FMD platform, including demographic characteristics (age, gender, height, and ethnicity) and clinical characteristics 
(number of pregnancies, use and duration of oral contraception, age at diagnosis of FMD, angiographic subtype of FMD, symptoms of FMD at diagnosis, and associated atheroma lesions), data concerning the first visit [seated office systolic and diastolic blood pressure (BP), body weight, serum creatinine, smoking habit, and number of antihypertensive medications], and vascular imaging (arterial beds explored, imaging modality, type, and site of lesions for each vascular bed). Furthermore, the investigators had to provide to the study coordinator (A.P.) fully anonymized images of the FMD lesion that led to the diagnosis. In case of disagreement, the diagnosis was discussed in a clinico-radiologic meeting at the coordinating centre, in cooperation with the referring investigator. The final decision to include or not the patient was made by the coordinator and his team, thus ensuring consistency in diagnostic criteria and interpretation of the images. At the time of each follow-up visit and/or imaging test performed, investigators were invited to fill in the platform the new clinical data, vascular imaging, and therapeutic procedures, if any. The authors state that the study complies with the Declaration of Helsinki.

All inclusions were carefully checked by M.P., P.D., and/or A.P. and queries were sent to the centres as needed.

After resolution of all queries, the database was locked on 1 May 2019, exported, and analysed using $\mathrm{R}$ software version 3.2.2. ${ }^{10}$ Continuous variables were expressed as mean \pm SD or median and interquartile range (IQR) according to their distribution; categorical variables were expressed as counts and percentage. Continuous variables were compared using the Student's test or the Mann-Whitney test. Categorical variables were compared using the $\chi^{2}$ test. A multinomial logistic regression (multivariate analysis) was performed to identify predictors of multivessel involvement, and of presence of FMD-related aneurysm and/or dissection, using both forward and backward methods. Multivariate analysis included all relevant variables [demographic features, inaugural manifestations of FMD (hypertension, stroke ...), FMD subtype, family history, and disease characteristics] shown to be significantly different in univariate analysis. A $P$ value $<0.05$ was considered statistically significant.

\section{Results}

\subsection{Demographic and clinical characteristics}

One thousand twenty-two patients were enrolled in 46 centres from 22 countries (five outside Europe, representing 11\% of the whole series) between 1 December 2015 and 30 April 2019 (database lock). Mean age at FMD diagnosis was $46 \pm 16$ years, patients were predominantly women (82\%), Caucasians (88\%) and of the multifocal subtype (72\%). About $86 \%(n=864)$ of patients had hypertension. Nineteen\% $(n=192)$ were smokers. The mean body mass index (BMI) and estimated glomerular filtration rate (eGFR) were $25 \pm 5 \mathrm{~kg} / \mathrm{m}^{2}$ and $92 \pm 40 \mathrm{~mL} / \mathrm{min} /$ $1.73 \mathrm{~m}^{2}$ (CKD-EPI equation), ${ }^{11}$ respectively. Finally, only $3 \%$ of patients $(n=31)$ reported a family history of FMD (Table 1$)$.

\subsection{FMD presenting symptoms and vascular bed involvement}

Hypertension was the most frequent presenting symptom (72\%). Seventeen\% of patients $(n=170)$ were diagnosed with FMD after referral for pulsatile tinnitus, $12 \%(n=117)$ for neurological symptoms (such as transient ischaemic attack-TIA, stroke, subarachnoid haemorrhage, and Claude Bernard-Horner syndrome), and $8 \%(n=84)$ for headache. Finally, in 26 patients (3\%), FMD was an incidental finding.

The prevalence of multivessel FMD, assessed in the subset of 488 patients who underwent full vascular screening (renal, cerebrovascular, and visceral/limb arteries) was $57 \%(n=280)$. One hundred and eightytwo patients (37\%) had FMD lesions in 2 vascular beds, 73 patients (15\%) in 3 vascular beds, and 25 patients (5\%) in 4 or more vascular beds. Among patients screened for each vascular bed, the proportion of patients with renal, cerebrovascular, visceral, and lower limb arteries FMD was $91 \%, 63 \%, 21 \%$, and 31\%, respectively (Table 1 and Figure 1).

Table I Overall characteristics of patients enrolled in the European/International FMD Registry

\begin{tabular}{|c|c|}
\hline No. of patients analysed & 1022 \\
\hline Age at diagnosis (years), mean $\pm \mathrm{SD}$ & $45.8 \pm 15.9$ \\
\hline Females (\%) & $831 / 1022(81.5)$ \\
\hline Caucasians (\%) & $885 / 1012(87.5)$ \\
\hline Systolic BP $(\mathrm{mmHg})$, mean $\pm \mathrm{SD}$ & $139.7 \pm 23.3$ \\
\hline Diastolic BP (mmHg), mean \pm SD & $84.6 \pm 14.4$ \\
\hline Hypertension (\%) & $864 / 1008(85.6)$ \\
\hline Age at hypertension diagnosis (years), mean \pm SD & $37.1 \pm 15.3$ \\
\hline No. of antihypertensive drugs, median (IQR) & $2(1-3)$ \\
\hline Current smokers (\%) & $192 / 1002(19.3)$ \\
\hline $\mathrm{BMI}$, mean $\pm \mathrm{SD}$ & $24.5 \pm 4.8$ \\
\hline eGFR CKD-EPI $\left(\mathrm{mL} / \mathrm{min} / 1.73 \mathrm{~m}^{2}\right)$, mean $\pm \mathrm{SD}$ & $91.8 \pm 39.6$ \\
\hline \multicolumn{2}{|l|}{ Presentation of FMD } \\
\hline Hypertension/renovascular presentation (\%) & $734 / 1018(72.0)$ \\
\hline Cerebrovascular presentation & $171 / 1011(11.6)$ \\
\hline Stroke $(\%)$ & $80 / 1011(7.9)$ \\
\hline TIA (\%) & $30 / 1011(3.0)$ \\
\hline Subarachnoid haemorrhage (\%) & $33 / 1011(3.2)$ \\
\hline Claude Bernard-Horner syndrome (\%) & 20/1011 (2.0) \\
\hline \multicolumn{2}{|l|}{ Other presentations } \\
\hline Headache (\%) & $84 / 1004(8.4)$ \\
\hline Pulsatile tinnitus (\%) & $170 / 1004(16.9)$ \\
\hline Incidental finding (\%) & $26 / 1004(2.6)$ \\
\hline Multifocal FMD (\%) & $740(72.3)$ \\
\hline Coexisting atherosclerotic lesions (\%) & $171 / 1012(16.9)$ \\
\hline Multivessel FMD ${ }^{\mathrm{a}}(\%)$ & $280 / 488(57.4)$ \\
\hline \multicolumn{2}{|l|}{$\begin{array}{l}\text { Numbers of patients (\%) in whom lesions } \\
\text { were found/numbers of patients (\%) screened } \\
\text { for each vascular bed }\end{array}$} \\
\hline Renal arteries & $855 / 943(90.7)$ \\
\hline Cerebrovascular arteries & $391 / 625(62.6)$ \\
\hline Visceral arteries & $161 / 760(21.2)$ \\
\hline Lower extremity arteries & $87 / 283(30.7)$ \\
\hline At least one aneurysm in any vascular bed (\%) & $220 / 1019(21.6)$ \\
\hline At least one dissection in any vascular bed (\%) & $57 / 1021(5.6)$ \\
\hline $\begin{array}{l}\text { At least one vascular bed treated with } \\
\text { revascularization (\%) }\end{array}$ & $531 / 1022(51.9)$ \\
\hline Family history of FMD (\%) & $31 / 1018(3.0)$ \\
\hline
\end{tabular}

BMI, body max index; BP, blood pressure; CKD-EPI, Chronic Kidney Disease Epidemiology Collaboration; eGFR, estimated glomerular filtration rate; FMD, fibromuscular dysplasia; TIA, transient ischaemic attack.

assessed in the subset of patients who underwent full vascular screening (renal, cerebrovascular, visceral/limb arteries). 
The prevalence of FMD-related aneurysms and dissections in the whole cohort was of $22 \%$ and $6 \%$, respectively. About $52 \%$ of patients $(n=531)$ underwent at least an endovascular and/or surgical intervention.

\subsection{Subgroup analysis}

\subsubsection{Focal vs. multifocal FMD}

Compared with patients with multifocal FMD $(n=740)$, patients with focal FMD $(n=282)$ were younger at diagnosis of FMD ( $39 \pm 16$ years vs. $49 \pm 15, P$ value $<0.001)$ and hypertension $(32 \pm 15$ years vs. $39 \pm 15, P$ value $=0.001)$ and more frequently males (31 vs. $14 \%, P$ value $=0.001)$ (Table 2). They also had a lower prevalence of multivessel (16\% vs. $41 \%$, $P$ value $=0.001)$ and bilateral FMD, both in renal $(21 \%$ vs. $41 \%, P$ value $=0.001)$ and cerebrovascular $(11 \%$ vs. $29 \%, P$ value $=0.001)$ arterial beds. Finally, they had less aneurysms $(11 \%$ vs. $26 \%, P$ value $=0.006)$ and coexisting atherosclerotic lesions $(12 \%$ vs. $19 \%, P$ value $=0.008)$, but underwent more endovascular and/or surgical interventions (70\% vs. $45 \%, P$ value $=0.001)$.

\subsubsection{Men vs. women}

Compared to women with FMD, men were significantly younger at diagnosis of both FMD ( $42 \pm 17$ vs. $47 \pm 16$ years, $P$ value $=0.001)$ and hypertension ( $34 \pm 16$ vs. $38 \pm 15$ years, $P$ value $=0.02)$, had more frequently focal FMD ( $46 \%$ vs. $23 \%, P$ value $=0.001)$ and less bilateral cerebrovascular lesions (17\% vs. $26 \%, P$ value $=0.02)($ Table 3$)$. Furthermore, men had a higher prevalence of arterial dissections than women (14\% vs. $4 \%, P$ value $=0.001$ ), while no significant difference was found in terms of prevalence of arterial aneurysms (men: $19 \%$ vs. women: $22 \%, P$ value $=0.3$ ).

\subsubsection{Elderly patients}

Compared to younger patients, patients $\geq 65$ years old at diagnosis of FMD had more often multifocal FMD ( $85 \%$ vs. $71 \%, P$ value $=0.002)$ and

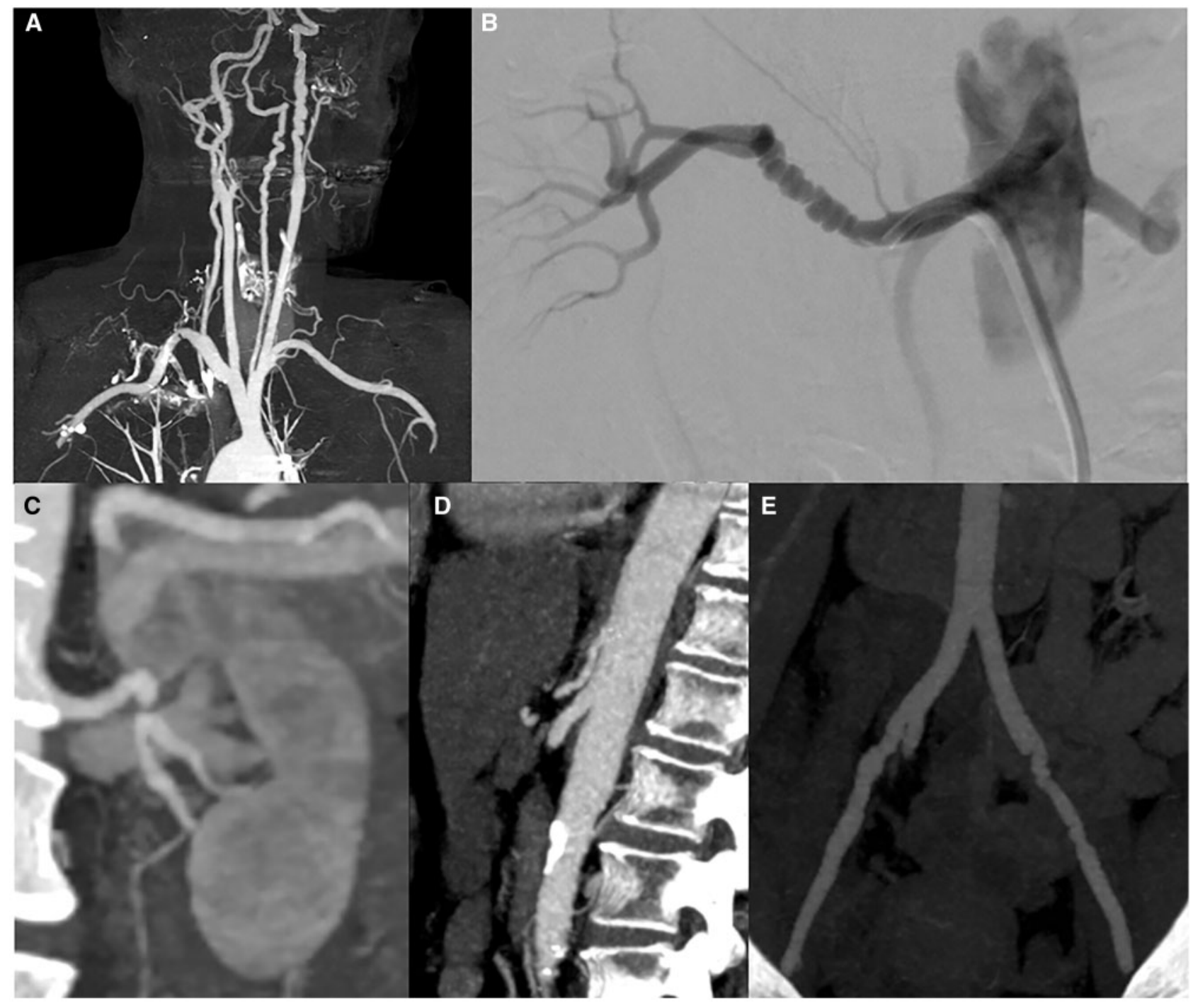

Figure I Examples of FMD lesions in various arterial beds. (A) Multifocal stenosis of the right internal carotid artery, of the left vertebral artery and of the left internal carotid artery. (B) Multifocal stenosis of the mid-distal segment of the right renal artery. (C) Severe focal stenosis of the distal segment of the left renal artery. (D) Multifocal stenosis of the coeliac trunk. (E) Bilateral multifocal stenosis of iliac common arteries. 
Table 2 Main distinctive features of patients with multifocal/focal FMD

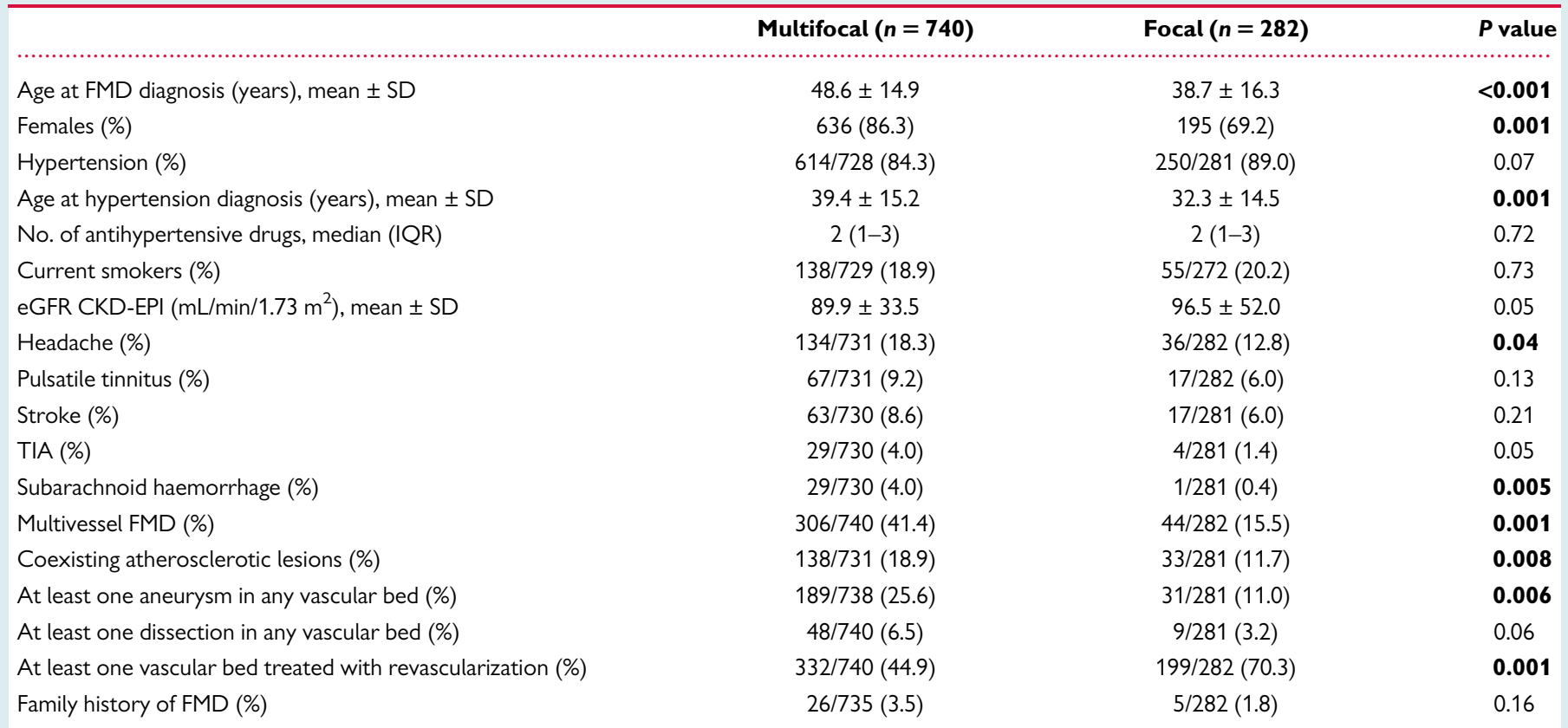

CKD-EPI, Chronic Kidney Disease Epidemiology Collaboration; eGFR, estimated glomerular filtration rate; FMD, fibromuscular dysplasia.

$P$ values $<0.05$ are highlighted in bold.

tended to have a more widespread disease (multivessel disease: $42 \%$ vs. $33 \%, P$ value $=0.08)($ Table 3$)$. Older patients also had a higher rate of coexisting atherosclerotic lesions ( $33 \%$ vs. $15 \%, P$ value $=0.004)$ but lower eGFR levels ( $69 \pm 24$ vs. $95 \pm 40 \mathrm{~mL} / \mathrm{min} / 1.73 \mathrm{~m}^{2}, P$ value $\left.<0.001\right)$. Finally, they underwent less interventional procedures (31\% vs. $55 \%, P$ value $=0.001$ ).

\subsection{Predictors of multivessel disease, aneurysms, and dissections}

We looked for predictors of multivessel disease (Table 4), aneurysms (Table 5), and dissections (Table 6), both in univariate and multivariate analysis.

In multivariate regression analysis (forward analysis), predictors of multivessel FMD were: age at diagnosis of FMD (OR/per year 1.02, 95\% $\mathrm{Cl}$ [1.00-1.03], $P$ value $=0.001)$, stroke/cerebrovascular presentation (OR 2.42, 95\% Cl [1.39-4.18], $P$ value $=0.001$ ), eGFR (OR per $\mathrm{ml} / \mathrm{min}$ $0.99,95 \% \mathrm{Cl}$ [0.98-0.99], $P$ value $=0.007)$, presence of at least one aneurysm (OR 4.31, 95\% Cl [3.05-6.13], $P$ value $<0.001$ ) or at least one dissection (OR 2.92, 95\% Cl [1.56-5.64], $P$ value $=0.001)$ in any vascular bed, multifocal FMD (OR 3.00, 95\% Cl [2.03-4.55], $P$ value $=0.001)$ and family history of FMD (OR 3.15, 95\% Cl [1.43-7.11], $P$ value $=0.005)$.

Predictors of the presence of aneurysm were multivessel (OR 3.99, $95 \% \mathrm{Cl}$ [2.89-5.57], $P$ value $<0.001)$ and multifocal $(\mathrm{OR} 1.91,95 \% \mathrm{Cl}$ [1.26-2.98], $P$ value $=0.003)$ FMD. Predictors of the presence of dissection were age at diagnosis of FMD (OR/per year 1.02, 95\% Cl [1.01-1.05], $P$ value $=0.03$ ), male gender (OR 4.35, 95\% Cl [2.33-7.69], $P$ value $=0.005)$, stroke/neurovascular presentation (OR $2.19,95 \% \mathrm{Cl}$ $[1.01-4.52], P$ value $=0.04$ ), and multivessel FMD (OR 3.15, 95\% $\mathrm{Cl}$ [1.74-5.87], $P$ value $=0.001)$. In contrast, hypertension/renovascular presentation was negatively correlated both with presence of aneurysms
$(\mathrm{OR} 0.63,95 \% \mathrm{Cl}[0.42-0.96], P$ value $=0.03)$ and dissections (OR 0.30, $95 \% \mathrm{Cl}[0.16-0.56], P$ value $=0.001)$.

For all 3 analysis, the same predictors were identified using backward analysis (data not shown).

\section{Discussion}

We performed a detailed analysis of the first 1022 patients enrolled in the European/International FMD Registry, including 46 centres from 22 countries, with emphasis on comparison between different subsets of patients and predictors of widespread disease and complications.

First, we confirmed the distinctive features of focal vs. multifocal FMD, as established by Savard et al. ${ }^{12}$ Compared to patients with multifocal FMD, patients with focal FMD were 10 years younger, more frequently males and had a much lower prevalence of bilateral and multivessel FMD.

Secondly, in agreement with previous reports from large datasets, we documented a high prevalence of multivessel FMD: $57 \%$ in the European/International FMD Registry, vs. $66 \%$ in the French-Belgian ARCADIA Registry (48\% not including aneurysms and dissections) ${ }^{6}$ and $55 \%$ in the last update of the US FMD Registry. ${ }^{2}$

Third, we reported the characteristics and predictors of multivessel FMD. In agreement with the ARCADIA study, ${ }^{6}$ patients with multivessel disease were more likely to have multifocal FMD or stroke/cerebrovascular presentation. Intriguingly also, patients with multivessel disease were older than patients with single-vessel disease in both registries. Whether this reflects the progression of FMD from single-vessel to multivessel disease over time is currently unknown and is in contrast with expert opinion that de novo FMD lesions only seldom appear. ${ }^{13}$ Other additional predictors of multivessel FMD reported for the first time in 
Table 3 Main distinctive features of female/male and younger/older patients with FMD

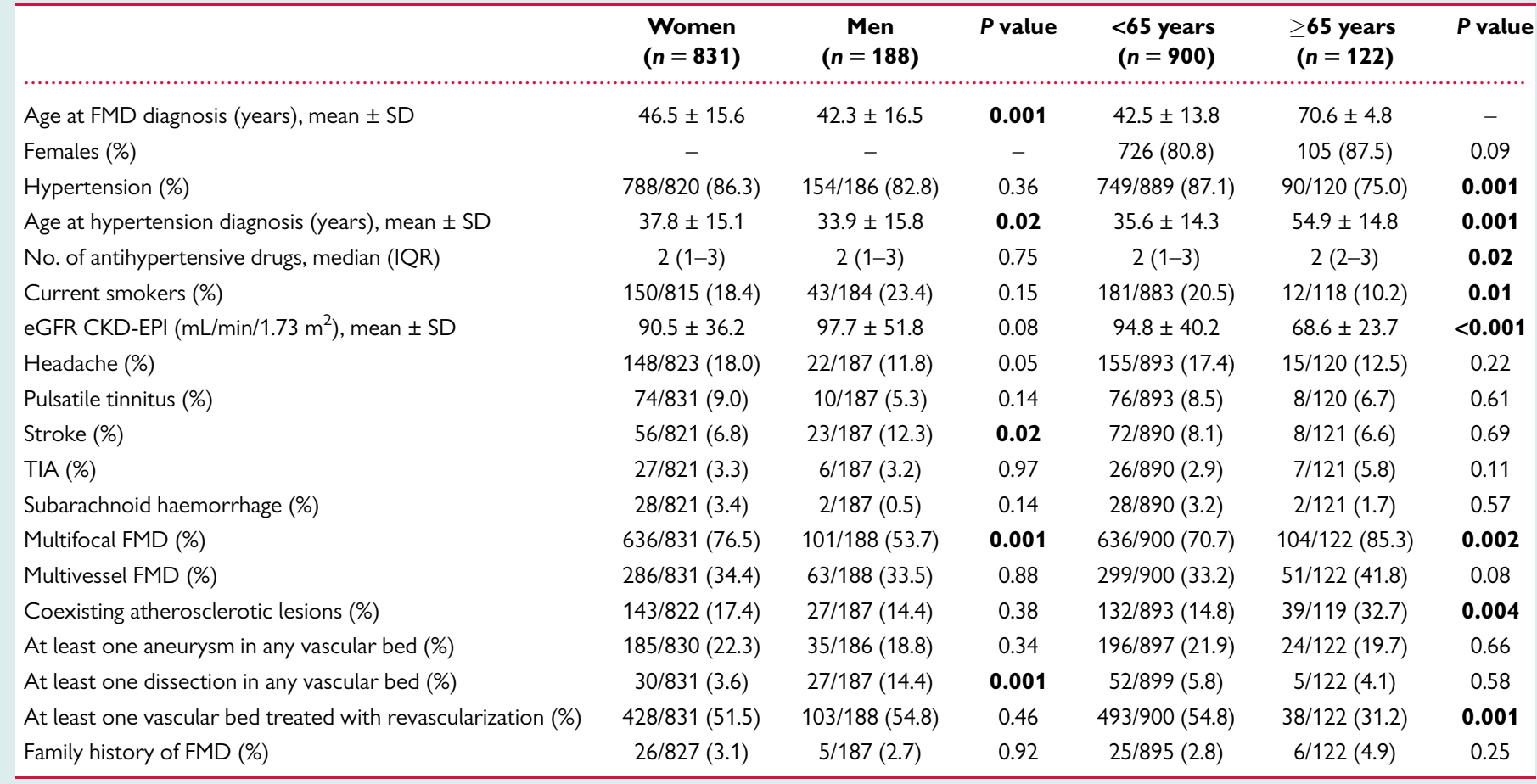

CKD-EPI, Chronic Kidney Disease Epidemiology Collaboration; eGFR, estimated glomerular filtration rate; FMD, fibromuscular dysplasia.

$P$ values $<0.05$ are highlighted in bold.

Table 4 Predictors of multivessel FMD in patients with FMD enrolled in the European/International FMD Registry

\begin{tabular}{|c|c|c|c|c|}
\hline \multirow[t]{2}{*}{ Variable } & \multicolumn{2}{|c|}{ Univariate analysis } & \multicolumn{2}{|c|}{ Multivariate analysis } \\
\hline & Odds ratio $(95 \% \mathrm{CI})$ & $P$ value & Odds ratio $(95 \% \mathrm{CI})$ & $P$ value \\
\hline Age at diagnosis of $\mathrm{FMD}^{\mathrm{a}}$ & $1.03(1.02-1.04)$ & 0.001 & $1.02(1.01-1.03)$ & 0.001 \\
\hline Hypertension/renovascular presentation & $0.64(0.44-0.92)$ & 0.005 & $0.74(0.51-1.07)$ & 0.10 \\
\hline Stroke/neurovascular presentation & $2.19(1.37-3.50)$ & 0.009 & $2.42(1.39-4.18)$ & 0.001 \\
\hline eGFR ${ }^{b}$ & $0.99(0.90-0.99)$ & 0.02 & $0.99(0.98-0.99)$ & 0.007 \\
\hline Coexisting atherosclerotic lesions & $1.79(1.28-2.50)$ & 0.001 & $1.37(0.96-1.95)$ & 0.07 \\
\hline At least one aneurysm in any vascular bed & $4.57(3.33-6.30)$ & $<0.001$ & $4.31(3.05-6.13)$ & $<0.001$ \\
\hline At least one dissection in any vascular bed & $3.85(2.19-6.97)$ & 0.006 & $2.92(1.56-5.64)$ & 0.001 \\
\hline Multifocal FMD & $3.94(2.77-5.73)$ & 0.001 & $3.00(2.03-4.55)$ & 0.001 \\
\hline Family history of FMD & $2.43(1.18-5.06)$ & 0.02 & $3.15(1.43-7.11)$ & 0.005 \\
\hline
\end{tabular}

this dataset include the presence of aneurysm (OR: 4.32) or dissection (OR 3.16) in at least one vascular bed, as well as family history of FMD (OR 3.00).

Fourth, we documented the prevalence of arterial aneurysms and dissections in our multicentre cohort. While the prevalence of aneurysms (21.6\%) was similar to that observed in the US $(22.7 \%)^{2}$ and ARCADIA $(26.0 \%)^{6}$ registries, the prevalence of arterial dissections was substantially lower (5.6\% vs. $28.1 \%$ and $15.1 \%$, respectively), probably due to predominance of Hypertension/Nephrology centres with focus on renovascular FMD vs. Neurology centres dealing with carotid/vertebral dissections in our Registry.

Fifth, we reported for the first time — at least in Europe - predictors of aneurysms and dissections in a wide dataset of patients with FMD. With the exception of multivessel FMD, which was associated with both dissections and aneurysms, predictors of either complication were different: multifocal FMD for aneurysms vs. higher age at diagnosis and male gender for dissections. The latter is in agreement with the higher frequency of arterial dissection in men vs. women documented in the US 
Table 5 Predictors of the presence of aneurysm in patients with FMD enrolled in the European/International FMD Registry

\begin{tabular}{|c|c|c|c|c|}
\hline \multirow[t]{2}{*}{ Variable } & \multicolumn{2}{|c|}{ Univariate analysis } & \multicolumn{2}{|c|}{ Multivariate analysis } \\
\hline & Odds ratio $(95 \% \mathrm{Cl})$ & $P$ value & Odds ratio $(95 \% \mathrm{Cl})$ & $P$ value \\
\hline Age at diagnosis of FMD ${ }^{a}$ & $1.01(0.99-1.02)$ & 0.06 & $1.00(0.99-1.00)$ & 0.48 \\
\hline Hypertension/renovascular presentation & $0.57(0.38-0.85)$ & 0.002 & $0.63(0.42-0.96)$ & 0.03 \\
\hline Multivessel FMD & $4.57(3.33-6.27)$ & $<0.001$ & $3.99(2.89-5.57)$ & $<0.001$ \\
\hline Multifocal FMD & $3.03(2.01-4.72)$ & 0.001 & $1.91(1.26-2.98)$ & 0.003 \\
\hline
\end{tabular}

FMD, fibromuscular dysplasia.

${ }^{\mathrm{a} O R}$ per year.

Table 6 Predictors of the presence of dissection in patients with FMD enrolled in the European/International FMD Registry

\begin{tabular}{|c|c|c|c|c|}
\hline \multirow[t]{2}{*}{ Variable } & \multicolumn{2}{|c|}{ Univariate analysis } & \multicolumn{2}{|c|}{ Multivariate analysis } \\
\hline & Odds ratio $(95 \% \mathrm{Cl})$ & $P$ value & Odds ratio $(95 \% \mathrm{Cl})$ & $P$ value \\
\hline Age at diagnosis of FMD ${ }^{a}$ & $1.03(1.01-1.05)$ & 0.001 & $1.02(1.01-1.05)$ & 0.03 \\
\hline Male gender & $3.95(2.24-6.94)$ & 0.001 & $4.35(2.33-7.69)$ & 0.005 \\
\hline Hypertension/renovascular presentation & $0.23(0.13-0.42)$ & 0.001 & $0.30(0.16-0.56)$ & 0.001 \\
\hline Stroke/neurovascular presentation & $3.78(1.83-7.32)$ & 0.001 & $2.19(1.01-4.52)$ & 0.04 \\
\hline
\end{tabular}

FMD, fibromuscular dysplasia.

${ }^{\mathrm{a} O R}$ per year.

FMD registry. ${ }^{14,15}$ This male predominance of (mostly carotid) dissection is in sharp contrast with the overwhelming female predominance of spontaneous coronary artery dissection, a disease often associated with extra-coronary FMD, ${ }^{16,17}$ showing that the association between dissection and gender may be vessel-specific.

Sixth, for the first time in Europe, we documented characteristics differentiating men vs. women and older vs. younger patients with FMD. Regarding gender differences, besides a higher prevalence of focal FMD and a four-fold increased prevalence of dissection in men, men were also slightly younger at diagnosis of FMD and hypertension and had a higher prevalence of stroke. These last findings are at odds with those of a preliminary report of the US Registry for FMD. ${ }^{15}$ They may partly reflect the fact that screening for FMD is less often performed in male than female patients, unless there is severe or early hypertension and/or cerebrovascular complications.

The proportion of patients diagnosed at 65 years or older was consistent with that of the US FMD Registry (12\% vs. $16 \%) .{ }^{18}$ However, characteristics of older patients slightly differed between both registries. While European elderly patients differed from younger patients by a slightly lower prevalence of hypertension at diagnosis, higher age at hypertension diagnosis and a lower prevalence of active smoking, US elderly patients reported less often headache and pulsatile tinnitus compared to younger patients, and had an increased prevalence of hypertension but less arterial dissections. ${ }^{18}$ Again, to what extent this reflects differences in natural history and/or distinct referral and exploration biases in both registries deserves further investigation.
While the prevalence of atherosclerotic lesions was expectedly higher in older than younger patients enrolled in the European/ International FMD Registry, it remains surprisingly low (33\%). As a matter of comparison, in the Cardiovascular Health Study, ${ }^{19}$ including 5888 participants aged $\geq 65$ years, the prevalence of carotid atherosclerotic plaques was $77 \%$. In agreement with the lower prevalence of cardiovascular events in elderly patients from the US Registry, ${ }^{18}$ this may reflect survival or inclusion biases. Alternatively, it may support the common belief that patients with FMD are somehow protected from atherosclerosis.

\subsection{Limitations}

Our work has a number of limitations: (i) only 3\% of cases of FMD were diagnosed incidentally. Therefore, our findings mostly apply to symptomatic FMD; (ii) non-Caucasian patients remain underrepresented (12.5\%), though to a lesser extent than in the US Registry (8.7\%); (iii) the contribution of regions of Europe such as Scandinavia, Germany, and Eastern Europe is still insufficient; (iv) Neurology centres remain a minority compared to Nephrology/Hypertension centres; ( $v$ ) information on intake of antiplatelet agents-which was not recommended in Europe when the Registry was established-plasma lipids and fasting glycaemia/history of diabetes was not captured; (vi) only half of patients (48\%) were explored for all vascular beds. However, the subgroup of fully explored patients did not differ from the other patients enrolled in the Registry, and predictors of multivessel FMD in the whole cohort were consistent with those identified in the subset of fully explored patients (data not shown); 


\section{Typical features of patients with multifocal/focal FMD*, multivessel/single-vessel FMD, and FMD with aneurysm(s) or dissections(s) based on findings of the European / International FMD registry}
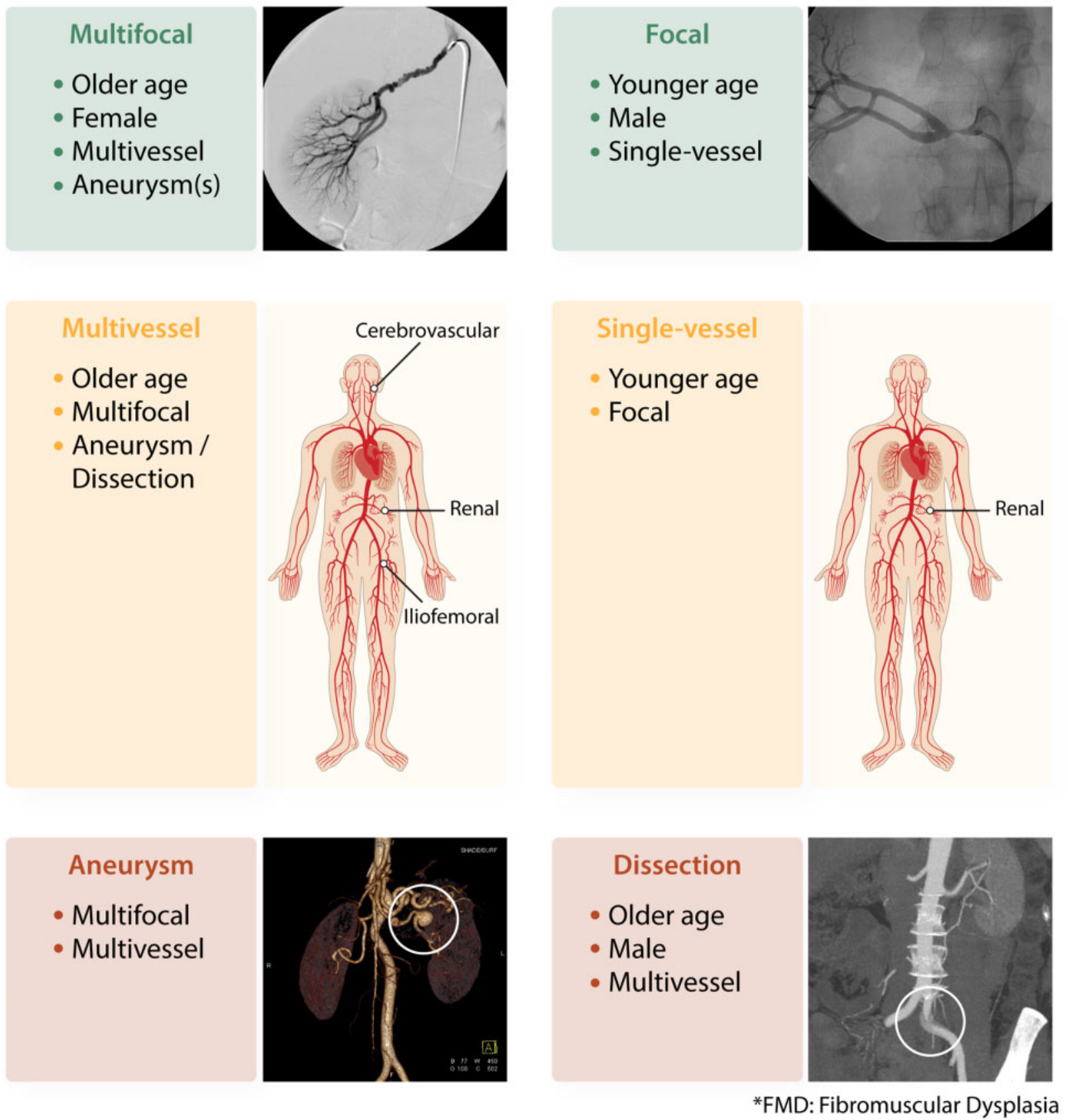

Figure 2 Typical features of patients with multifocal/focal FMD, multivessel/single-vessel FMD, and FMD with aneurysm(s) or dissection(s) based on findings of the European/International FMD Registry. FMD, fibromuscular dysplasia.

and (vii) finally, the current analysis is cross-sectional, therefore the course of the disease cannot be assessed and predictors of multivessel FMD, presence of aneurysms and dissections need confirmation in prospective studies.

\subsection{Conclusion}

The European/International FMD Registry is a unique resource incorporating patients from 46 centres from Europe and beyond vs. 16 for the
French-Belgian ARCADIA study ${ }^{6}$ and 13 in the US Registry. ${ }^{2}$ This wide recruitment is expected to increase the generalizability and external validity of our findings. This first analysis including over 1000 patients allowed large-scale characterization of distinct profiles of patients with FMD and, more importantly, identification of a unique set of independent predictors of widespread disease, aneurysms and dissections (Figure 2), paving the way for targeted screening, management, and follow-up of FMD. 
Beyond scientific findings, the involvement of a wide network of investigators in European/International FMD Registry will undoubtedly contribute to improve and harmonize screening and management of FMD across Europe and beyond, which will in its turn facilitate large-scale testing of new hypothesis and evaluation of different management strategies.

\section{Authors' contributions}

Conception and design of the work: Alexandre Persu and Marco Pappaccogli. Acquisition of data: Marco Pappaccogli, Ewa WarchołCelińska, Aurélien Lorthioir, Laurence Amar, Lucas S Aparicio, Rosa Maria Bruno, Patrick Chenu, Peter de Leeuw, Tine De Backer, Philippe Delmotte, Zivka Dika, Daniel Gordin, Hilde Heuten, Yoshio Iwashima, Jean-Marie Krzesinski, Abraham A Kroon, Lucia Mazzolai, Esteban Poch, Pantelis Sarafidis, Christophe Seinturier, Wilko Spiering, Patricia Van der Niepen, Daan van Twist, Adriana Visonà, Jean-Claude Wautrecht, Helena Witowicz, Jianzhong Xu, Aleksander Prejbisz, Andrzej Januszewicz, and Michel Azizi. Analysis of data: Silvia Di Monaco, Marco Pappaccogli, Philippe Delmotte, and Laurent Toubiana. Interpretation of data: Marco Pappaccogli and Alexandre Persu. Critical revision for important intellectual content: Christophe Beauloye and Michel Azizi. Drafting of the work: Marco Pappaccogli and Alexandre Persu.

\section{Acknowledgements}

A.P. wishes to acknowledge Prof. P.-F. Plouin, X. Jeunemaitre, and M. Azizi (HEGP, Paris, France) and Prof. A. Morganti (University of Milan, Milan, Italy) for their relentless support for the European/International FMD Registry and Initiative, as well as L. Toubiana (INSERM, UMR_S1142, LIMICS, Paris, France) for his crucial role in the establishment and update of the FMD platform. The authors are also deeply indebted to the leadership of the European Society of Hypertension (ESH) and the European Society for Vascular Medicine (ESVM) for their constant support.

\section{Notes}

Investigators from the European/International FMD Registry and Initiative (FEIRI):

Argentina: Lucas S. Aparicio (Hospital Italiano de Buenos Aires, Buenos Aires, Argentina). Belgium: Alexandre Persu, Marco Pappaccogli, Christophe Beauloye, Patrick Chenu, Frank Hammer, Pierre Goffette, Parla Astarci, André Peeters, Robert Verhelst and Miikka Vikkula (Cliniques Universitaires Saint-Luc, Brussels); Patricia Van der Niepen and Frank Van Tussenbroek (Universitair Ziekenhuis Brussel, Brussels); Tine De Backer, Sofie Gevaert, Dimitri Hemelsoet and Luc Defreyne (Universitair Ziekenhuis Gent, Gent); Hilde Heuten, Laetitia Yperzeele and Thijs Van der Zijden (Universitair Ziekenhuis Antwerpen, Antwerpen); Jean-Philippe Lengelé (Grand Hôpital De Charleroi, Charleroi); Jean-Marie Krzesinski and Muriel Sprynger (CHU Sart-Tilman, Liège); Philippe Delmotte (Hôpital Ambroise Paré, Mons); Peter Verhamme and Thomas Vanassche (UZ-Gasthuisberg, Leuven); Pasquale Scoppettuolo and Jean-Claude Wautrecht (University Hospital ULB Erasme, Brussels, Belgium); Wouter Vinck (GZA ziekenhuizen - campus Sint-Augustinus, Wilrijk). Bulgaria: Vassilev Dobrin and Yaneva Teodora (Medical University, Sofia). China: Jiguang Wang and Jianzhong $\mathrm{Xu}$ (Shanghai Institute of Hypertension, Department of Hypertension, Ruijin
Hospital, Shanghai Jiaotong University School of Medicine, Shanghai, China). Croatia: Bojan Jelaković and Zivka Dika (Department of Nephrology, Arterial Hypertension, Dialysis and Transplantation, University Hospital Center Zagreb, School of Medicine University of Zagreb, Zagreb, Croatia). Finland: Daniel Gordin, Ilkka Tikkanen, Maarit Venermo and Research Nurse Anita Mäkelä (Helsinki University Hospital, Helsinki, Finland). France: Pierre-François Plouin, Xavier Jeunemaitre, Laurent Toubiana, Michel Azizi, Laurence Amar, Antoine Chédid, Elie Mousseaux and Aurélien Lorthioir (Hopital Européen Georges Pompidou and Université de Paris, Paris); Emmanuel Touzé (University of Caen, Caen); Olivier Ormezzano, Christopher Seinturier, Frédéric Thony ( $\mathrm{CHU}$ de Grenoble-Université Grenoble Alpes, Grenoble). Germany: Felix Mahfoud and Saarraaken Kulenthiran (Saarland University Hospital, Homburg/Saar). Greece: Pantelis Sarafidis, Alexia Piperidou and Michael Doumas (Hippokration Hospital, Thessaloniki); George S. Stergiou (Sotiria Hospital, National and Kapodistrian University of Athens, Medical School, Greece); Demetrios Vlahakos (national and Kapodistrian University of Athens Medical School. Athens, Greece). Ireland: Caitriona Canning (St. James's Hospital, Dubin, Ireland). Israel: Yehonatan Sharabi (Sheba Medical Center, Tel Hashomer \& Tel Aviv University, Israel). Italy: Alberto Morganti (University of Milan, Milan); Rosa Maria Bruno, Stefano Taddei and Caterina Romanini (Department of Clinical and Experimental Medicine University of Pisa, Pisa), llaria Petrucci (Sant'Anna School of Advanced Studies, Pisa); Franco Rabbia, Marco Pappaccogli and Silvia Di Monaco (AOU Città della Salute e della Scienza, Torino); Gian Paolo Rossi and Silvia Lerco (University Hospital, Padova); Pietro Minuz, Giancarlo Mansueto, Sergio De Marchi, Denise Marcon (Università di Verona, Verona); Patrizia Salice (Unità Operativa di Cardiologia Fondazione Policlinico Mangiagalli Regina Elena IRCCS, Milano); Adriana Visonà and Paola Bigolin (UOC Angiologia, Castelfranco Veneto; European Society for Vascular Medicine (ESVM) Centre); Viviana Zingaretti and Rosario Cianci (Hypertension Center, Policlino Umberto I, Roma); Marialuisa Zedde (Neurology Unit, Stroke Unit, AUSL-IRCCS di Reggio Emilia, Reggio Emilia); Maria Chiara Matteucci (Arterial Hypertension Unit, Pediatric Cardiology and Cardiac Surgery Department, Bambino Gesù Children's Hospital, Roma). Japan: Yoshio Iwashima (Department of Nephrology and Hypertension, Dokkyo Medical University, Tochigi, Japan); Osami Kawarada (Department of Cardiovascular Medicine, Ikuwakai Memorial Hospital, Japan); Yoshito Kadoya (Department of Cardiovascular Medicine, Kyoto Prefectural University of Medicine, Kyoto, Japan). The Netherlands: Daan J van Twist (Department of Internal Medicine, Zuyderland Medical Centre, Sittard/Heerlen); Bram Kroon and Peter de Leeuw (Maastricht University Medical Center, Maastricht); Wilko Spiering (University Medical Center Utrecht, Utrecht); Bert-Jan van den Born (Academic Medical Centre, University of Amsterdam, Amsterdam). Norway: Aud Høieggen, Martin Skage Sommer (Oslo University Hospital, Oslo, Norway). Poland: Andrzej Januszewicz, Ewa Warchoł-Celińska, Aleksander Prejbisz, Adam Witkowski, Helena Witowicz, Jacek Kądziela, Aleksandra Soplińska, Krzysztof Pieluszczak, Katarzyna Jóżwik-Plebanek, Magdalena Januszewicz, Elżbieta Florczak, Piotr Dobrowolski (National Institute of Cardiology, Warsaw) and the investigators of the ARCADIA-POL network. Slovakia: Eva Szabóová, Marek Hudák and Matej Moščovič (Department of Angiology, PJ Šafárik University in Košice and East Slovak Institute of Cardiovascular Disease, Košice). Spain: Juan Diego Mediavilla and Fernando Jaen Aguila (Virgen of The Nieves University Hospital, Granada, Spain); Anna Oliveras (Hospital del Mar, Barcelona); Julian Segura and Jose C. Prado (Hospital Universitario 12 de Octubre, Madrid); Nicolas Roberto Robles (Hospital 
Infanta Cristina, Badajoz); Esteban Poch, Enrique Montagud-Marrahi, Alicia Molina, Elena Guillen (Department of Nephrology and Kidney Transplantation, University of Barcelona, Barcelona) and Marta Burrel (Department of Radiology, Hospital Clinic, Barcelona); Patricia Fernàndez De la Llama and Luz San Miguel-Amigo (Hypertension Unit, Nephrology Department, Fundació Puigvert, Barcelona); Antonio J Barros-Membrilla (Cardiology Department, Hospital de la Santa Creu i Sant Pau, Barcelona). Sweden: Anders Gottsäter (Skåne University Hospital, Malmö, Sweden). Switzerland: Gregor Wuerzner (Service of Nephrology and Hypertension, Department of Medicine, Lausanne University Hospital - CHUV, Lausanne); Lucia Mazzolai and Giacomo Buso (Division of Angiology, Heart and Vessel Department, Lausanne University Hospital - CHUV, Centre of rare vascular diseases and RAVAD registry, Lausanne). Tunisia: Faiçal Jarraya and Hanen Chaker (Service de Néphrologie, CHU Hédi Chaker, Sfax, Tunisie). United Kingdom: David Adlam (University of Leicester and the NIHR Leicester Biomedical Research Centre, UK); Constantina Chrysochou (Salford Royal NHS Foundation Trust, The National Registry of Rare Kidney Diseases - RaDaR -, Greater Manchester); Neeraj Dhaun, Robert W. Hunter, lain Maclntyre and David Webb (University of Edinburgh, Edinburgh).

\section{Conflict of interest: none declared.}

\section{References}

1. Plouin P-F, Perdu J, La Batide-Alanore A, Boutouyrie P, Gimenez-Roqueplo A-P, Jeunemaitre X. Fibromuscular dysplasia. Orphanet J Rare Dis 2007;2:28.

2. Gornik HL, Persu A, Adlam D, Aparicio LS, Azizi M, Boulanger M, Bruno RM, De Leeuw P, Fendrikova-Mahlay N, Froehlich J, Ganesh SK, Gray BH, Jamison C, Januszewicz A, Jeunemaitre $X$, Kadian-Dodov D, Kim ESH, Kovacic JC, Mace P, Morganti A, Sharma A, Southerland AM, Touzé E, Van der Niepen P, Wang J, Weinberg I, Wilson S, Olin JW, Plouin PF; Working Group 'Hypertension and the Kidney' of the European Society of Hypertension (ESH), Society for Vascular Medicine (SVM). First International Consensus on the diagnosis and management of fibromuscular dysplasia. J Hypertens 2019;37:229-252. Vasc Med 2019;24:164-189.

3. Cragg AH, Smith TP, Thompson BH, Maroney TP, Stanson AW, Shaw GT, Hunter DW, Cochran ST. Incidental fibromuscular dysplasia in potential renal donors: longterm clinical follow-up. Radiology 1989;172:145-147.

4. Touzé E, Southerland AM, Boulanger M, Labeyrie PE, Azizi M, Bouatia-Naji N, Debette S, Gornik HL, Hussain SM, Jeunemaitre X, Joux J, Kirton A, Le Hello C, Majersik JJ, Mocco J, Persu A, Sharma A, Worrall BB, Olin JW, Plouin PF. Fibromuscular dysplasia and its neurologic manifestations: a systematic review. JAMA Neurol 2019;76:217-226.

5. Olin JW, Froehlich J, Gu X, Bacharach JM, Eagle K, Gray BH, Jaff MR, Kim ES, Mace P, Matsumoto AH, McBane RD, Kline-Rogers E, White CJ, Gornik HL. The United States Registry for fibromuscular dysplasia: results in the first 447 patients. Circulation 2012;125:3182-3190.

6. Plouin PF, Baguet JP, Thony F, Ormezzano O, Azarine A, Silhol F, Oppenheim C, Bouhanick B, Boyer L, Persu A, Hammer F, Gosse P, Mounier-Vehier C, Le Hello C,
Jeunemaitre X, Azizi M, Amar L, Chatellier G, Mousseaux E, Touzé E, ARCADIA Investigators. High prevalence of multiple arterial bed lesions in patients with fibromuscular dysplasia: the ARCADIA Registry (Assessment of Renal and Cervical Artery Dysplasia). Hypertension 2017;70:652-658.

7. Persu A, Van der Niepen P, Touzé E, Gevaert S, Berra E, Mace P, Plouin PF, Jeunemaitre $\mathrm{X}$; Working Group 'Hypertension and the Kidney' of the European Society of Hypertension and the European Fibromuscular Dysplasia Initiative. Revisiting fibromuscular dysplasia: rationale of the European Fibromuscular Dysplasia Initiative. Hypertension 2016;68:832-839.

8. Toubiana L, Ugon A, Giavarini A, Riquier J, Charlet J, Jeunemaitre X, Plouin PF, Jaulent MC. A "pivot" model to set up large scale rare diseases information systems: application to the Fibromuscular Dysplasia Registry. Stud Health Technol Inform 2015; 210:887-891.

9. Jaulent MC, Assélé-Kama A, Savard S, Giavarini A, Touzé E, Jeunemaitre X, Ugon A, Plouin PF, Toubiana L. Building a semantic interoperability framework for care and research in fibromuscular dysplasia. Stud Health Technol Inform 2015;216: 217-221.

10. R Development Core Team. R: a language and environment for statistical computing. Vienna (Austria): R Foundation for Statistical Computing; 2008. http://www.Rproject.org.

11. Levey AS, Stevens LA, Schmid CH, Zhang YL, Castro AF III, Feldman HI, Kusek JW, Eggers P, Van Lente F, Greene T, Coresh J, CKD-EPI (Chronic Kidney Disease Epidemiology Collaboration). A new equation to estimate glomerular filtration rate. Ann Intern Med 2009;150:604-612.

12. Savard S, Steichen O, Azarine A, Azizi M, Jeunemaitre X, Plouin PF. Association between 2 angiographic subtypes of renal artery fibromuscular dysplasia and clinical characteristics. Circulation 2012;126:3062-3069.

13. Kadian-Dodov D, Goldfinger JZ, Gustavson S, Olin JW. Natural history of cervical artery fibromuscular dysplasia and associated neurovascular events. Cerebrovasc Dis 2018;46:33-39.

14. Kadian-Dodov D, Gornik HL, Gu X, Froehlich J, Bacharach JM, Chi YW, Gray BH, Jaff MR, Kim ES, Mace P, Sharma A, Kline-Rogers E, White C, Olin JW. Dissection and aneurysm in patients with fibromuscular dysplasia: findings from the U.S. registry for FMD. J Am Coll Cardiol 2016;68:176-185.

15. Kim ESH, Olin JW, Froehlich JB, Gu X, Bacharach JM, Gray BH, Jaff MR, Katzen BT, Kline-Rogers E, Mace PD, Matsumoto AH, McBane RD, White CJ, Gornik HL. Clinical manifestations of fibromuscular dysplasia vary by patient sex: a report of the United States Registry for Fibromuscular Dysplasia. J Am Coll Cardiol 2013;62: 2026-2028.

16. Prasad M, Tweet MS, Hayes SN, Leng S, Liang JJ, Eleid MF, Gulati R, Vrtiska TJ. Prevalence of extracoronary vascular abnormalities and fibromuscular dysplasia in patients with spontaneous coronary artery dissection. Am J Cardiol 2015;115: 1672-1677.

17. Saw J, Starovoytov A, Humphries K, Sheth T, So D, Minhas K, Brass N, Lavoie A, Bishop H, Lavi S, Pearce C, Renner S, Madan M, Welsh RC, Lutchmedial S, Vijayaraghavan R, Aymong E, Har B, Ibrahim R, Gornik HL, Ganesh S, Buller C, Matteau A, Martucci G, Ko D, Mancini G. Canadian spontaneous coronary artery dissection cohort study: in-hospital a 30-day outcomes. Eur Heart J 2019;40: 1188-1197.

18. Bagh I, Olin JW, Froehlich JB, Kline-Rogers E, Gray B, Kim ESH, Sharma A, Weinberg I, Wells BJ, Gu X, Gornik HL. Association of multifocal fibromuscular dysplasia in elderly patients with a more benign clinical phenotype: data from the US Registry for Fibromuscular Dysplasia. JAMA Cardiol 2018;3:756-760.

19. Cao JJ, Arnold AM, Manolio TA, Polak JF, Psaty BM, Hirsch CH, Kuller LH, Cushman M. Association of carotid artery intima-media thickness, plaques, and C-reactive protein with future cardiovascular disease and all-cause mortality: the Cardiovascular Health Study. Circulation 2007;116:32-38.

\section{Translational perspective}

Fibromuscular dysplasia (FMD) is nowadays considered as a systemic arterial disease, warranting brain-to-pelvis vascular imaging in all patients. However, most current evidence is derived from a limited number of expert centres. Furthermore, one size may not fit all. Based on analysis of the first 1000 patients enrolled in the European/International FMD registry ( 46 centres; 22 countries) we characterized distinct patient profiles according to FMD subtype, age and gender and identified predictors of widespread disease, aneurysms and dissections, paving the way for individualized management and follow-up. Further studies will allow refining patient characterization according to ethnicity, genetic profile, and imaging biomarkers. 